\title{
Bilateral Traumatic Foot Drop - An Unusual Injury - Isolated Case Report
}

\author{
Vibhav Gandhi ${ }^{1}$, Mohit Jindal ${ }^{1 *}$, Navneet Aujla ${ }^{2}$, Keerty Garg ${ }^{3}$ and Nishant Kumar ${ }^{1}$ \\ ${ }^{1}$ Department of Orthopaedics, Kalpana Chawla Govt Medical College, India \\ ${ }^{2}$ Senior Resident, Govt. Multi Speciality Hospital, India \\ ${ }^{3}$ Department of anaesthesia, Kalpana Chawla Govt Medical College,India
}

Submission: August 28, 2018; Published: September 07, 2018

*Corresponding author: Mohit Jindal, Department of Orthopaedics, Kalpana Chawla Govt Medical College, Tel:+91 9729617945;

Email: mohitjindal2006@gmail.com

\begin{abstract}
Introduction: Foot drop is defined as weakness of foot and ankle dorsiflexion. Acute unilateral foot drop is relatively common entity whereas bilateral foot drop is rare. Slowly progressive as well as acute onset foot drop due to spinal problems are mentioned in literature, traumatic bilateral foot drop has not been reported till date.

Case Report: A 45-year-old male presented with an unusual mode of injury with hot rod passing obliquely through his left lower limb and right buttock leading to neurogenic foot drop on right side and foot drop due to tendomuscular scarring on left side. He was managed in a staged manner and a favourable outcome was achieved.

Discussion: Multiple techniques of tendon transfer are described in literature for foot drop. Tendon to tendon split transfer of tibialis posterior to tibialis anterior and EHL-EDL is one among them. Good functional outcome can be achieved by management plan tailoured to patient
\end{abstract} and his needs

Keywords: Traumatic; Bilateral foot drop; Tendon transfer

\section{Introduction}

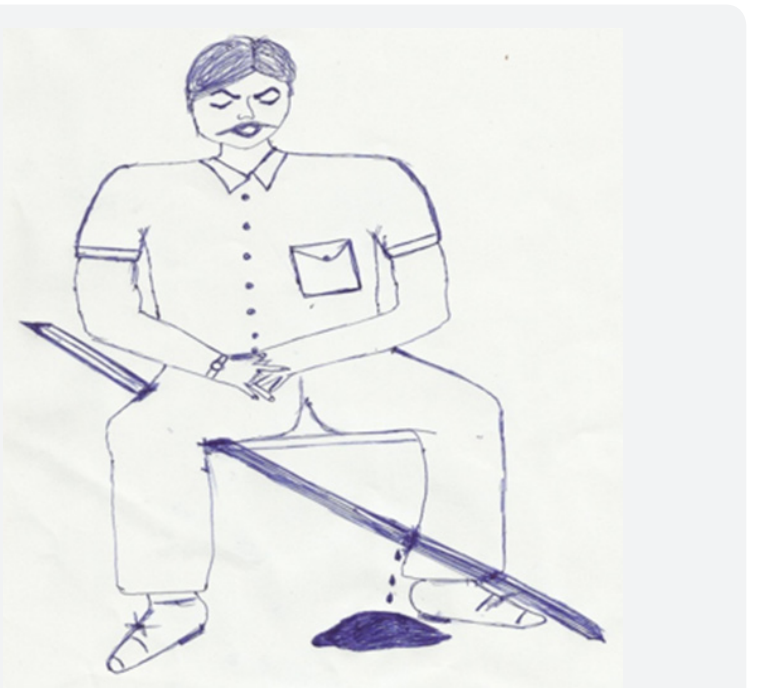

Figure 1: Is a rough sketch to explain the mechanism of injury with a hot rod passing obliquely through left lower leg and right buttock.

Foot drop is defined as weakness of tibialis anterior, extensor hallucis longus and extensor digitorum longus muscles[1].Unilateral foot drop is a common entity[2] and is mostly traumatic in nature. Bilateral foot drop is also known entity but is rare in comparison to unilateral foot drop. Bilateral foot drop reported in literature are mostly insidious and slowly progressive, reported in patients with anorexia nervosa[3] hypothyroidism[4], crohn's disease[5], neuroschistosomiasis[6] and intracranial pathologies[7]. Acute onset bilateral foot drop is also reported in cases of disc herniation[2] and cauda equina syndrome[8]. There is no mention of traumatic acute onset bilateral foot drop. Here we present a case of unusual mode of injury sustained at work place by hot iron rod passing obliquely through left lower leg and right buttock resulting in neurogenic foot drop on right side along with loss of dorsiflexion on left side due to tendomuscular charring of anterior compartment of leg(Figure 1).

\section{Case Report}

A 45-year-old male presented with open fracture of distal third tibia left with associated bone loss (external fixator in situ) with non-healing wound of size $8 \times 6 \mathrm{~cm}$ and atrophied anterior compartment of left leg with stiffness of tendoachilles with resultant equinus deformity at left foot. On right side foot drop was associated with sensory loss in distribution of common 
peroneal nerve with a healed wound of size $3 \times 3 \mathrm{~cm}$ on the right gluteal region. He had sustained injury with a hot rod passing obliquely through left lower leg and right buttock at work place 3 months prior to presentation(Figure 1). Patient wanted amputation of left foot as non-healing wound and associated deformity were interfering in performing his daily activities. He was explained prognosis, functional outcome and sequelae. His condition was managed in a staged manner.

In first stage debridement of wound, removal of fixator and cross leg fasciocutaneous flap over non-healing left leg wound was done and deformity corrected intra operatively by manipulation, maintained using plaster slab. In second stage (4 weeks after first stage) autogenous bone grafting of left distal tibia fracture and tendon transfer of tibialis posterior tendon through interosseous route for right side foot was performed Figure 2 shows the clinical picture of the patient post stage 1 showing healed fascio cutaneous flap. Figure 3 shows the radiographic picture showing union of the distal tibial fracture Left side.

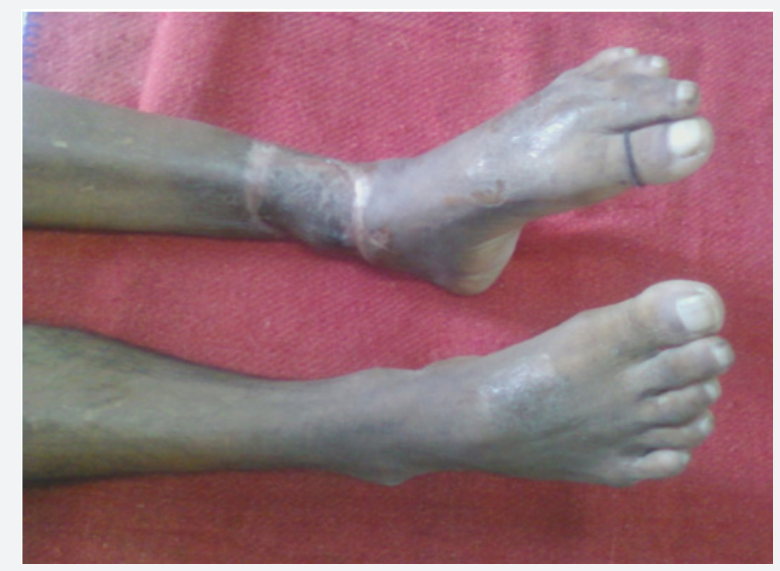

Figure 2: Clinical picture of the patient post stage 1.

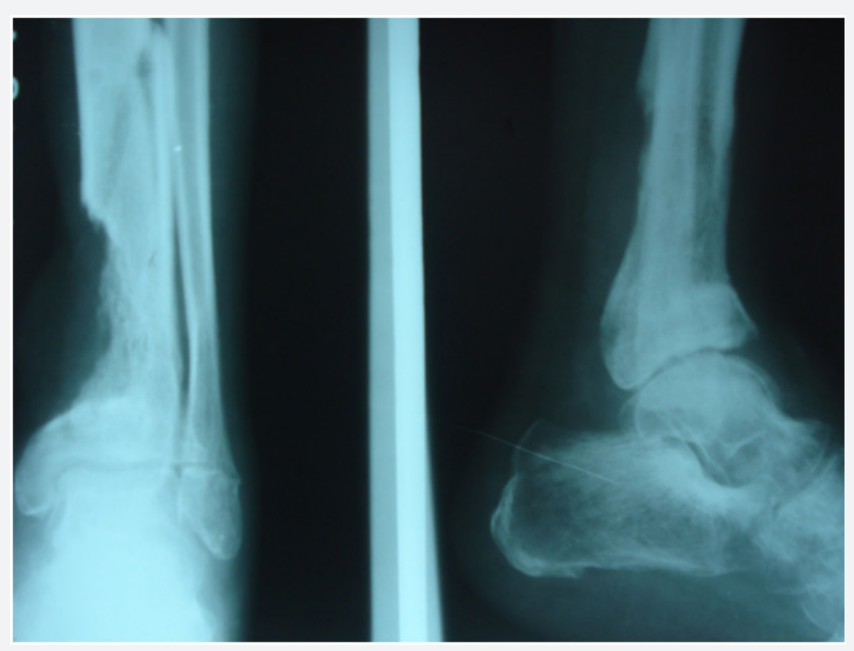

Figure 3: Radiographic picture showing union of the distal tibial fracture Left side.

\section{Result}

The tibia fracture non-union got united satisfactorily over a period of 6 months with patient's left foot maintained in neutral position secondary to posterior release and resulting in a functionally better foot. On right side foot drop was corrected secondary to tibialis posterior tendon transfer with ankle range of movement of 40 degrees after physiotherapy.

\section{Discussion}

Common peroneal nerve is the most common lower extremity palsy characterised by supinated equinovarus deformity and foot drop. Dynamic tendon transposition represents the gold standard for surgical restoration of dorsiflexion of a paralysed foot[9]. Transposition of tibialis anterior is the most accepted reconstructive method to correct foot drop[10]. In 1933, Ober described anterior transposition of tibialis posterior tendon through circumtibial route. Watkins et al. [11]in 1954 reported the same transfer through transosseous route[12].Anderson [13] and Richard [14]provided with tendon to tendon technique for fixation of transferred tendon. In this case we have used tendon to tendon technique, tibialis posterior tendon was split into two slips, one attached to tibialis anterior and another slip to extensor digitorum and hallucis with good result as similar to Anderson [13] and Srinivasan et al. [15]. While Watkins et al. [12] and Lipscomb \& Sanchez [16] used tendon to bone fixation technique with success. With the split tendon technique, the problem of toe drop, and balanced dorsiflexion are resolved as mentioned in studies of Anderson [13], Srinivasan et al. [15] and Ozkan [17]. Vigasioet al. [9]introduced a double tendon transfer surgery where tibialis posterior is transferred to tibialis anterior and flexor digitorum longus to EHL and EDL.Yeganeh [10]mentioned use of three tendons- tibialis posterior, flexor halluces longus and flexor digitorum longus to bring balanced dorsiflexion at foot. In conclusion there are various techniques for tendon transposition but the technique of choice is tailored according the patient and his needs.

\section{Conclusion}

Staged treatment approach tailored according to the underlying mechanism of injury can achieve good functional outcome for the patient in cases of complex and unusual injury.

\section{Conflict of Interest}

None.

\section{References}

1. Iizuka Y, Iizuka H, Tsutsumi S, Nakagawa Y, Nakajima T, et al. (2009) Foot drop due to lumbar degenerative conditions: Mechanism and prognostic factors in herniated nucleus pilposus and lumbar canal stenosis. J Neurosurg Spine 10(3): 260-264.

2. Kertman H, Gurer B, Yimaz ER, Sekerci Z (2015) Acute bilateral isolated foot drop: Report of two cases. Asian J Neurosurg 10(2): 123-125.

3. Kershenbaum A, Jaffa T, Zeman A, Boniface S (1997) Bilateral foot drop in patient with anorexia nervosa. Int J Eat Disord 22(3): 335-337. 
4. Bhansali A, Chandran V, Ramesh J, Kashyap A, Dash RJ (2000) Acute myxoedema: An unusual presenting manifestation of hypothyroid myopathy. Postgrad Med J 76: 99-100.

5. Gabriella SE, Gunashekhar NP (1994) Bilateral foot drop, weight loss and rectal bleeding as an acute presentation of crohn's disease. Postgrad Med J 70(828): 762-763.

6. Wilbers J, Idema A, Gijtenbeek A (2010) A bilateral foot drop due to neuroschistosomiasis. J Neurol 257(5): 853-855.

7. Eskandary H, Hamzei A, Yasamy MT (1995) Foot drop following brain lesion. Surg Neurol 43(1): 89-90.

8. Chang HS, Nakagawa H, Mizuno J (2000) Lumbar herniated disc presenting with cauda equine syndrome. Long term follow up of four cases. Surg Neurol 53(2): 100-105.

9. Vigasio A, Marcoccio I, Patelli A, Mattiuzzo V, Prestini G. New tendon transfer for correction of drop-foot in common peroneal nerve palsy. Clin Orthop Relat Res 466: 1454-1466.

10. Yeganeh MM (2016) Triple tendon transfer for correction of foot deformity in common peroneal nerve palsy. Foot Ankle Int 37(6): 665669.
11. Ober FR (1933) Tendon transplantation in the lower extremity. N Engl J Med 209: 52-59.

12. Watkins MB, Jones JB, Ryder CT Jr, Brown TH Jr (1954) Transplantation of the posterior tibial tendon. J Bone Joint Surg Am 36: 1181-1189.

13. Anderson JG (1963) Foot drop in leprosy and its surgical corrections. Acta Orthop Scand 33: 151-171.

14. Richard BM (1989) Interosseous transfer of tibialis posterior for common peroneal nerve palsy. J Bone Joint Surg Br 71(5): 834-837.

15. Srinivasan H, Mukherjee SM, Subramaniam RA (1968) Two-tailed transfer of tibialis posterior for correction of foot-drop in leprosy. J Bone Joint Surg Br 50(3): 623-638.

16. Lipscomb PR, Sanchez JJ (1961) Anterior transplantation of the posterior tibial tendon for persistent palsy of the common peroneal nerve. J Bone Joint Surg Am 43(1): 60-66.

17. Ozkan T, Tuncer S, Ozturk K, Aydin A, Ozkan S (2007) Surgical restoration of drop foot deformity with tibialis posterior tendon transfer. Acta Orthop Traumatol Turc 41(4): 259-265.

\begin{tabular}{|l|}
\hline \multicolumn{1}{|c|}{ Your next submission with Juniper Publishers } \\
will reach you the below assets \\
- Quality Editorial service \\
- Swift Peer Review \\
- Reprints availability \\
- E-prints Service \\
- Manuscript Podcast for convenient understanding \\
- Global attainment for your research \\
- Manuscript accessibility in different formats \\
( Pdf, E-pub, Full Text, Audio) \\
- Unceasing customer service \\
Track the below URL for one-step submission \\
https://juniperpublishers.com/online-submission.php \\
\hline
\end{tabular}

